EPJ Web of Conferences 82, 01040 (2015)

DOI: $10.1051 /$ epjconf/20158201040

(C) Owned by the authors, published by EDP Sciences, 2015

\title{
The processes of formation of nitrogen oxides in the boiler furnace BKZ 320-140
}

\author{
N.V. Vizgavljust ${ }^{1}$, A.V. Starchenko ${ }^{2}$, A.V. Gil ${ }^{1}$ and T.S. Taylasheva ${ }^{1}$ \\ ${ }^{1}$ Tomsk Polytechnic University, Tomsk, Russia \\ ${ }^{2}$ Tomsk State University, Tomsk, Russia
}

\begin{abstract}
In this paper, a numerical study of the formation of nitrogen oxides in the combustion chamber based on the model created by Mitchell and Terbellom. The distribution of the height of the furnace temperature and the concentration of nitrogen oxides, as well as a comparison of numerical results with the data of field experiment.
\end{abstract}

Outdoor air pollution is one of the major problems of our time due to the imperfect human activities. Artificial man-made sources of air pollution are the most dangerous, and primarily related to the combustion processes of natural fuels [1]. Approximately $40 \%$ of the total air pollutants nitrogen oxides generated by thermal power plants, burning the fossil fuels. Predicting the formation of harmful substances from fossil fuel-fired thermal power plants is one of the major challenges for the energy sector. The use of numerical methods to study not only facilitates the solution of problems, but also allows you to work out a few options of the problem, to assess structural changes and optimization of engineering solutions for these objects.

In this paper we use numerical simulation of the generation of nitrogen oxides during the combustion of coal dust on the model created by Mitchell and Tarbell om [2]. This kinetic model is simple to use, as includes 13 reactions take into account the processes of exit and volatile combustion, combustion of coke particles. Model [2] gives the modern idea of aeromechanics processes leading to the generation of nitrogen oxides from the combustion of pulverized fuel [3].

Analytic study of the model-Mitchell-Tarbell held in the furnace boiler BKZ 320-140 followed by verification of the results obtained with the experimental data of field experiment [4].

Boiler BKZ 320-140 (see Fig. 1) burns brown coal Kansk-Achinsk [4]. Boiler designed monohull performance U-shaped layout with liquid slag removal. At around $11400 \mathrm{~m}$ from zero is to "survive", which separates the combustion chamber and the cooling chamber. Each of the two octagonal furnace extensions that make up the combustion chamber is equipped with four slot burners [4].

Calculations were performed using: aerothermodynamic and temperature fields obtained with the application package FIRE 3D [5]; the concentration of nitrogen oxides - application package FIRE $3 \mathrm{D}-\mathrm{NO}_{\mathrm{x}}$ [6], depending on the fuel supply speed under constant excess air at the exit of the furnace and a load of 1,27 boiler $300 \mathrm{t} / \mathrm{h}$. As an indicator of the organization staged combustion accepted ratio $\delta=\mathrm{B}_{1} / \mathrm{B}_{\mathrm{p}}$, where $\mathrm{B}_{1}-$ fuel consumption for the lower tier burners, $\mathrm{B}_{\mathrm{p}}-$ fuel for the boiler.

This is an Open Access article distributed under the terms of the Creative Commons Attribution License 4.0, which permits unrestricted use, distribution, and reproduction in any medium, provided the original work is properly cited. 


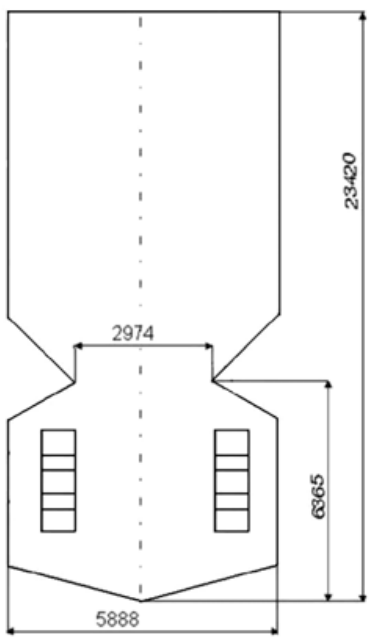

Figure 1. Geometrical characteristics of the furnace boiler BKZ 320-140.

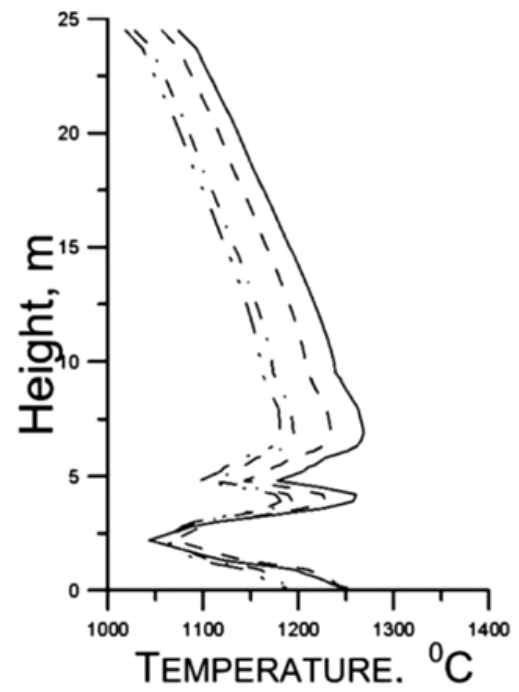

$a$

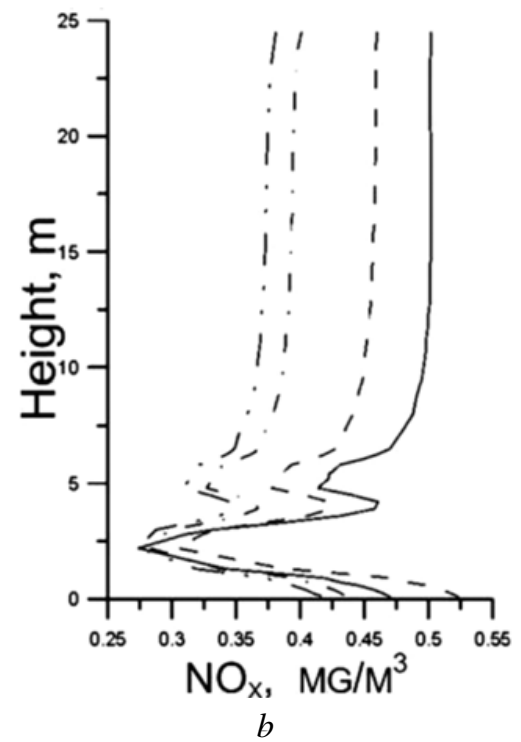

Figure 2. Distribution of the height of the furnace: a) an average cross-sectional temperature, b) is the concentration of nitrogen oxides: $-\delta=0,38--\delta=0,55-\bullet-\bullet-\delta=0,68-\bullet--\delta=0,72$.

Figure 2 shows the distribution in height of the combustion chamber temperature and the concentration of oxides of nitrogen, homogenized in horizontal sections.

The maximum amount of $\mathrm{NO}_{\mathrm{x}}$ formed in the zone of active burning (see Fig. 2b), which is characterized by higher values of the temperature of the two-phase flow (see Fig. 2a). The process of formation of oxides is in two comparatively large areas located below and above the burner zone. The concentration of nitrogen oxides in the course of the plume does not change significantly, it suggests that the formation of oxides generally occurs at the stage of burnout volatile. The formation of nitrogen oxides in the cooling chamber in small quantities (10-15\%) of the final concentration at the outlet of the furnace is due to residual nitrogen in the fuel particles carried away from the combustion chamber. 


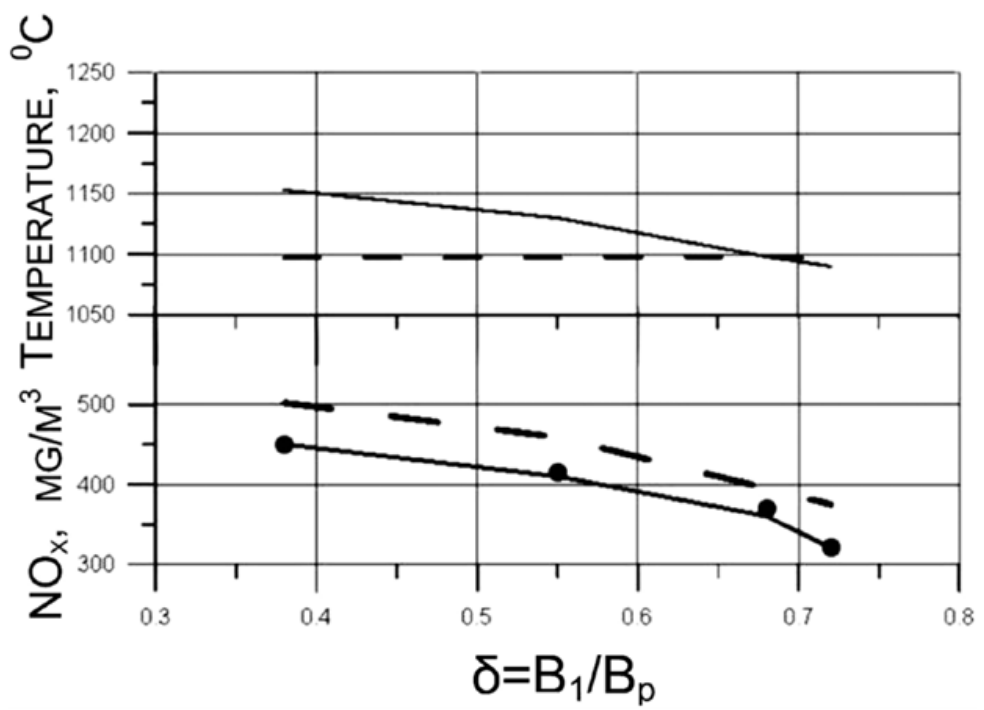

Figure 3. Distribution of the output of the furnace temperature and the concentration of nitrogen oxides, depending

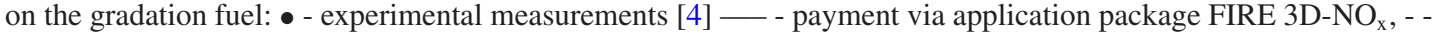
- - payment on the normative method [7].

Figure 3 shows a comparison of the numerical results with field studies [4] and calculation methods [7], depending on the speed the fuel at the outlet of the furnace.

Figure 3 shows that the developed numerical model has a high prediction accuracy of the generation of nitrogen oxides. In the future, can be used for pre-design and design solutions modernization of boiler units, and the organization staged combustion is effective method vnutritopochnogo suppression of nitrogen oxides in the furnaces of industrial boilers.

\section{References}

[1] Kotler V.R. Nitrogen oxides in the flue gas boilers - M .: Energoatomizdat, $1987-144$ p.

[2] Mitchell J.W., Tarbell J.M. A kinetic model of nitric oxide formation during coal combustion // American Institute of Chemical Engineers Journal. - 1982. - V. 28. - No 2. - P. 302-310

[3] Ivanova N.V., Starchenko A.V. Simulation of the formation of nitrogen oxides during the combustion of pulverized coal. // News TPU - Tomsk Polytechnic University, 2002, T. 305, No 2. - S. $147-151$

[4] Budilov O.I., Zavorin A.S. Experience to improve the environmental performance of the thermal power plant. - Tomsk .: Publisher "Red Flag", 1994 - 100 p.

[5] Zavorin A.S., Krasil'nikov S.V., Starchenko A.V. Software package for calculation and visualization of three-dimensional reacting turbulent flows in boilers // Problems using kanskoAchinsk coal power plants: Mater. Vseross. Scientific-practical conference. conf. - Krasnoyarsk: SibVTI, 2000 - S. 369-371

[6] Vizgavljust N.V., Starchenko A.V. Program to calculate the concentration of nitric oxide in the dust of a boiler furnace // Certificate of state registration of the computer No 2014611378. Bull. prog. 2014. - No 1

[7] Sinless A.N., Lime J.M., Schleifer B.M. Calculation of steam boilers. - M .: Energoatomizdat, 1991 - 240 pages 